\title{
Integral Development and Educational Renewal in Saskatchewan: A Visionary Process
}

\author{
Barbara Wotherspoon
}

University of Saskatchewan

\author{
Abstract \\ "We must educate to survive, critique and create." \\ (Berry, as cited in O’Sullivan, 1999, p. 8)
}

Transformative educators such as Thomas Berry, Brian Swimme, and Edmund O’Sullivan believe that the time has come for a shift away from the dominant Western educational ideology that focuses on achievement, individualism, and material success. They propose that education must become more than a system of banking information and standardized testing, and educators must be prepared to operate out of a much larger integrated worldview. They suggest that schools must provide balanced non-dualistic education that values students more for who they are than what they can achieve. In June 2008, the Saskatchewan Ministry of Education published a document which addresses similar concerns to those raised by Berry, Swimme, and O'Sullivan. The document entitled Renewed Objectives for the Common Essential Learning of Critical and Creative Thinking (CCT) and Personal and Social Development (PSD) recommends a number of key changes to existing educational policy in the areas of emotional, social and spiritual formation. The recommendations place emphasis on spiritual development, environmental awareness, ecological principles, human diversity, creative-ability development, and community-based achievement. This paper analyzes the educational need for renewal of current Western ideology and it supports the revamping of policy as proposed by the 2008 Ministry of Education document. It also discusses how the three principles of O'Sullivan's (1999) integral development theory towards transformative education may be helpful for enhancing the effective implementation of the 2008 CCT and PSD Ministry of Education document.

Keywords: integrated education; transformative education 


\section{Integral Development and Educational Renewal in Saskatchewan: A Visionary Process}

Last spring, I had the occasion to watch some kindergarten-aged children play a game of soccer. One team was wearing red vests and the other was in blue. The teacher was showing the children how one team could win by getting the ball away from the other team in order to score points. Two little girls forgot that they were supposed to be playing an organized sport; they were completely absorbed in smelling, touching, and talking to a group of flowers that had managed to avoid being trampled. The teacher encouraged them to come back to the game, and when they hesitated, she physically picked them up and pointed them in the direction that they were to run. Although I could see the benefits of being outside and being involved in physical exercise, I also felt a bit saddened because so early in their education, these youngsters were being introduced to standardization, competition, and disconnection from the natural world. I could only hope that the school system would not destroy their sense of awe, mystery, and imaginative play. (B. Wotherspoon, personal communication, 2010)

In June 2008, the Saskatchewan Ministry of Education published a document entitled Renewed Objectives for the Common Essential Learning of Critical and Creative Thinking (CCT) and Personal and Social Development (PSD). Headed by project developer and writer, Dr. Sandra Finney, a committee of 30 provincial curriculum developers recommended a number of key changes to existing educational policy. The renewal process involved renaming policy on Personal and Social Values and Skills (PSVS) to Personal and Social Development (PSD) in order to emphasize the developmental aspect of education in the area of emotional, social, and spiritual formation. It also involved synthesizing the objectives of the common essential learning of Personal and Social Development (PSD) with that of Critical and Creative Thinking (CCT) in a way that informed and strengthened each area, and targeted elements of CCT, PSD, and integrated CCT/PSD. In addition, the renewal committee placed emphasis on spiritual development, environmental awareness, ecological principles, human diversity, creative-ability development, and community-based achievement. The project was developed on the basis of 12 holistic, value-based underlying assumptions, and the document that was produced contains thorough explanations of the learning objectives, as well as substantial teacher guidelines, checklists, summaries, sample activities, mini-lessons, and resource suggestions for implementing CCT, PSD, and integrated CCT/PSD. What the document does not contain is an analysis of the educational need for a revamping of policy prior to 2008, or a discussion of the critical conceptual work of the committee members as they undertook the task of renewal. In addition, although the document states that it is directed towards the members of school communities and is meant to stimulate thinking, raise awareness, focus questions and dialogue, and facilitate understanding about CCT and PSD, the committee does not recommend a philosophical framework within which such discourse can take place.

This paper reviews three key concepts in an integral developmental approach for building toward the renewal envisioned by Finney (2008) and her committee. Education towards integral development as proposed by O'Sullivan (1999) in Transformative Learning is rooted in the work of Thomas Berry (1988), a renowned “ecologian,” who has developed the Twelve Principles for the Understanding of the Universe. Integral development is grounded in Berry's fourth principle, which states: The three basic laws of the universe at all levels of reality are differentiation, 
subjectivity, and communion. These laws identify the reality of the universe, the values of the universe, and the direction in which the universe is proceeding. At this critical moment in Earth's history, O'Sullivan explains that these three principles are not evolving as they should because humans have disrupted the order of the natural world by placing themselves above all other living things and causing mass destruction in the natural world. In order to realign the values of the individual with the proper ordering of the universe, O'Sullivan, along with Swimme and Berry (1992), recommend putting into practice the principles of differentiation, subjectivity, and communion. Differentiation celebrates the uniqueness of all life forms; subjectivity assumes that each being is a subject with a will to live and an attunement to its environment, and communion acknowledges the interconnection of all living things. When applied to education, the essence of these three evolving principles parallels the Twelve Assumptions underlying the Saskatchewan Ministry of Education document.

\section{Twelve Assumptions: Assessment and Analysis Warranted}

Finney's (2008) committee members list 12 Assumptions that form the basis of the renewal project, but their document does not give a background explanation of the reasons that change in educational policy is necessary. Their assumptions stand without any reference to past educational practices; they address the present modern-day need to create an educational atmosphere that is consistent with the democratic and multicultural nature of Saskatchewan society, a total school atmosphere in which people live their values and work together for the common good. Finney's committee suggests a process by which school staffs and school communities might discuss these 12 Assumptions. They acknowledge that the assumptions will not be accepted by all, and they realize that some may challenge the values and beliefs proposed in the renewal document. They recommend those involved in discussions about the assumptions respect each other's viewpoints and accept disagreements as part of the democratic process, and they encourage local groups to use disagreements as opportunities to learn and grow together and to share with others who are undertaking renewal.

Assumptions 7, 8, and 9 address the need for spiritual development because "humans are more than minds in bodies," and "human spirit is an essential aspect of wholeness" (Finney, 2008, p. 11). Assumption 4 states that no education is "value free" (Finney, 2008, p. 10). It expresses a belief in democracy, equality, social justice, and lifelong learning; it recognizes a need for independence, self-responsibility, living together in harmony, and sustaining life on the planet; and it emphasizes respect for all people and the environment. Assumption 1 states a need for improvement and sustainability towards a better quality of daily life, and Assumption 10 stresses a need for education that focuses on an understanding of biodiversity and practices related to sustaining the natural environment. Assumption 2 states that because the school is a microcosm of larger society, PSD caters to the needs that arise from "social ills" of society. Assumptions 3, 5, and 6 stress a need for a safe, respectful educational atmosphere where students can learn through questioning, making mistakes, and constructing personal meaning and purpose. Assumption 11 concludes that "attainment of values, attitudes, and disposition can neither be forced or [sic] guaranteed” (Finney, 2008, p. 12), and Assumption 12 describes the interdependent and interrelated nature of CCT and PSD.

Although the vision that is proposed by the renewal document does not analyze reasons for necessary change, it warrants some understanding of the broad context of the need for transformative education in today's mechanistic Western society. O’Sullivan (1999) proposes that "[o]ne of the preparations for the future is a sober assessment of the past, to see how the 
forces of the past are operating in the present moment” (p. 47). In order that educators might undergo such assessment, it is necessary that they fully understand and confront the historical development of current educational mechanistic practices that mandate a need for renewal. The provision of transformative education requires a creative and critical consciousness of the worldview that has caused many of the problems that exist in modern day schools. Purpel and McLaurin (2004) and O’Sullivan (1999) provide the background information necessary for educators to critically deconstruct educational practices that foster and support a mechanistic world view.

\section{Mechanistic World View: The Root of Educational Crisis From Two Perspectives}

In Reflections on The Moral and Spiritual Crisis in Education, Purpel and McLaurin (2004) state that educators "must have the courage not only to examine the nature and impact of [Western] culture but also to consider how [they] as individuals reflect the values and norms of the culture” (p. 73). Purpel and McLaurin offer insights about educational realities that work against the type of holistic value-based educational principles that Finney's (2008) committee has developed. Purpel and McLaurin describe three complex moral and spiritual paradoxes that currently exist in middleclass Western educational institutions:

1. Individualism/Community: Schools promote the growth of school spirit, school identity and school community, but they place much more emphasis on the development of personal identity, success and achievement (One only has to look at the practice of individual grading and standardized testing to realize the truth of this reality). This focus on personal success is "highly inappropriate preparation for an interdependent world in which the sense of justice, community, and compassion should be the overriding consideration” (Purpel \& McLaurin, 2004, p. 46).

2. Worth/Achievement: School policies stress the worth, dignity and uniqueness of each individual and they strongly discourage behaviours that create situations of unfairness or inequality, but at the same time, school practices often equate human worth and dignity with achievement. "The schools mirror the culture by giving its powerfully symbolic rewards to those who achieve more than others...this conviction must coexist with...our intense desire to....love others for who they are rather than for what they do or have" (Purpel \& McLaurin, 2004, p. 50).

3. Equality/Competition: An emphasis on individualism, competition, personal achievement and success works against the commitment to social equality. In shaky economic times, people are forced to make a choice between justice for all and personal survival. In schools, students confront a number of conflicting choices that mirror societal paradoxes.

Purpel and McLaurin (2004) also explore a number of conflicts that result when moral principles clash with educational practices, and although they are directed towards American education, many of their insights provide compelling reasons for educators to seriously consider Finney's (2008) committee's objectives for educational renewal in Saskatchewan. Some of the paradoxical dilemmas that Purpel and McLaurin present are as follows:

- Humans value giving and receiving compassion, but schools which stress individualism and achievement often promote sentimentality, which "distances” and "dehumanizes" the processes of mutuality, interdependence, and social responsibility. 
- Schools concentrate more on the unhealthy aspects of acting out of guilt than of "helping people to sort out their legitimate responsibilities and contribute to the development of the intellectual, psychological, and spiritual resources required to respond in a way that is fulfilling and meaningful” (Purpel \& McLaurin, 2004, p. 57).

- Schools value critical thinking, but at the same time put great stress on their own authority and power. Students are generally not allowed to be critical of their school environment.

- Schools which formerly integrated democracy and education (see Dewey,1916,) are now controlled by accountability (efficiency, productivity, discipline), and as a result, are more concerned with raising standards than with instilling values towards responsible citizenship.

- Western education faces a clash between a genuine belief in a common humanity and a suspicion of people from different cultures.

- True education requires questioning and developing one's own beliefs, but schools are rigid in their "sameness" and in their "right answers". This arrogance reflects a lack of humility, which is caused by a loss of faith that comes from those who are unable to find meaning and direction in life. Schools, which should overcome alienation, actually nurture it by demanding that students adhere to educational pursuits that hold no interest for them.

- In their concern for facilitating the individual pursuit of socioeconomic success, schools have become institutions that foster alienation rather than places that help students find meaning and fulfillment in life.

- Taking responsibility for reacting to the transgressions of the culture works against complacency in education.

- "Pseudoscience, narrowly defined academic goals, and predetermined answers are antithetical to serious educational inquiry, but they are excellent ways of facilitating the emphasis on grading and competition. They are effective control mechanisms and give a legitimate flavour to the hierarchical power structure in schools. Thus, schools are not terribly interested in faith or reason, truth or wisdom, but use them as part of the rhetoric of justifying the direction of enormous energy to the rather vulgar duty of helping people to make money and raise their status” (Purpel \& McLaurin, 2004, p. 71).

- Educators must confront the human impulse for self-deception and have the wisdom to discern its destructiveness. They must remember that they are both the cause and the effect of the system.

In Transformative Learning, O’Sullivan (1999) reiterates Purpel and McLaurin's (2004) arguments that educators have a "specific responsibility for forging a broad educational belief system" (p. 272), and he challenges educators to "enter into a deep cultural and personal reflection on educational paradigms that are operating at the deeper levels of consciousness" (p. 8). Like Purpel and McLaurin, O’Sullivan (1999) is critical of formal educational institutions that are "tailored to the needs of the consumer industrial society" (p. 43), but he identifies the current educational crisis as one in which schools are being structured to encourage the exploitation of the natural world to meet human consumption. O'Sullivan addresses the need for environmental sustainability that also appears as a renewal objective in the Saskatchewan 
Ministry of Education document. He claims "the fundamental educational task of our times is to make the choice for a sustainable global planetary habitat of interdependent life forms over and against the global competitive marketplace” (O’Sullivan , 1999, p. 45). He believes that we are living in a time of transition, and he advocates a "radical restructuring of all current educational directions” (O’Sullivan, 1999, p. 45). He recommends that a transformative and visionary educational framework is necessary for the movement to shift from product-oriented, individualized educational pursuits to organic, connected, value-based educational processes.

O’Sullivan (1999) proposes that what contemporary education lacks is a cosmological component that can "be functionally effective in providing a basis for an educational programme that would engender an ecologically sustainable vision of society in the broadest terms; what can be called a planetary vision” (p. 4). He quotes Abram (1996), who in The Spell of the Sensuous, discusses the lack of such a vision:

Clearly, something is terribly missing, some essential ingredient has been neglected, some necessary aspect of life has been dangerously overlooked, set aside, or simply forgotten in the rush toward a common world. In order to obtain the astonishing and unifying image of the whole earth whirling in the darkness of space, humans, it would seem, have had to relinquish something just as valuable - the humility and grace that comes from being fully a part of that whirling world. We have forgotten the poise that comes from living in storied relation and reciprocity with the myriad things, the myriad beings, that perceptually surround us...If we do not soon remember ourselves to our sensuous surroundings, if we do not reclaim our solidarity with the other sensibilities that inhabit and constitute those surroundings, then the cost of our human commonality may be our common extinction. (pp. 270-71)

O’Sullivan (1999) believes that the pre-eminent view of the world as a machine has led to the human disconnection with the wider biotic community and the natural world. He contrasts the mechanistic world view with that of Indigenous world views which have historically regarded the earth as a sacred, a spiritual, and a nurturing source of life which is intricately connected to humans and all other life forms. He states that a mechanistic map of the universe can no longer be used towards understanding the workings of the world, and he calls for a frame of reference that allows for the development of "a profoundly holistic and integral education that moves beyond mechanistic atomism” (O’Sullivan, 1999, p. 75). This framework is called integral development. To ensure that Renewed Objectives for the Common Essential Learning of Critical and Creative Thinking (CCT) and Personal and Social Development (PSD) are interpreted and implemented within a framework that supports the creative regenerations of educational practices in the areas of spiritual development, environmental awareness, ecological principles, human diversity, creative-ability development, and community-based achievement, this paper advocates the consideration of differentiation, subjectivity and communion, the three principles of integral development.

\section{The Integral Development Framework: A Transformative Vision of Education}

In an attempt to articulate a vision of transformation that transcends the limitations of Western systems, O’Sullivan (1999) suggests that the term "integral” goes beyond "holistic," in that it allows for the existence of harmony and disharmony within a creative system where all living forms evolve; the word development "presumes that all living processes are always in dynamic states of growth, decay and transformation” (p. 208). O’Sullivan theorizes that humans 
need to develop a consciousness of the three creative evolutionary principles of differentiation, subjectivity, and communion, as set out by the fourth universal principle of Berry (1984). The tendencies of differentiation, subjectivity, and communion identify the values and the realities that continually find expressions as the universe undergoes constant sequences of transformation. Berry and Swimme (1992) contend that in the context of transformation in the last century, humans have savagely plundered the earth by industrial exploitation, and as a result, the existence of a vast number of species, including the human species is now being threatened. The time has come for humans to become aware of our proper relationship to the planet and to the universe, and to recognize that the needs and rights of the planet are the needs and rights of the human. This personal consciousness raising involves understanding the interrelated principles of integral development, which at the most basic level defines the essence of creativity.

About differentiation, O’Sullivan (1999) states: "The cosmological task embedded in the process of differentiation is to articulate in the most developed sense who we are as persons and who we are as specific communities" (p. 223). The human species has arisen from the matrix of the earth, and humans are just one component of a vast multitude of living beings that have risen from the same earth. Within humanity, differentiation is evident within the tremendous variety of people from different ages, genders, races, ethnic backgrounds, and cultures. When the principle of differentiation is considered within the educational system, it celebrates that all students are unique multi-faceted beings that are gifted with inner intelligibility, individual identity, and a unique set of intellectual and creative abilities. In addition, it specifies that each student has a unique history in time and place; each represents a particular social, familial, ethnic, economic, racial, gender-based perspective, and each has an open destiny that is yet to be formed. Swimme (2001) explains, "Each being [is] glistening with freshness ontologically unique, never to be repeated. Each being is required. None can be eliminated or ignored, for not one is redundant" (p. 61-62). Differentiation recognizes that all school communities possess distinctive histories, capabilities, and possibilities. No two students and no two school communities can ever be the same, and education must be a process of evolutionary re-creation that meets the constantly changing needs of those it serves as it transforms itself in relation to the needs of the rest of the world. "The radical nature of differentiation is the creativity which brings with it the burden of being and becoming...unique in different ways from all that exists in the present and all that has existed in the past or that will exist in the future” (O’Sullivan, 1999 p. 223).

In describing the principle of subjectivity, O’Sullivan (1999) explores an organic aspect of all living species that works against mechanistic tendencies to objectify non-human beings. Subjectivity gives each living being an interior identity and formation, an inner spontaneity, an indwelling self, and a connection with the ultimate mystery of the cosmos. The universe consists of subjects such as elements, plants, animals, and humans, all of which are centres of spontaneity and sentience. Spontaneity is the ability of a living subject to organize itself, and species at all levels of the living universe are capable of self-organization and self-regulation. Sentience is the innermost ability to feel and to experience. There are several opinions about which species are capable of this quality, ranging from only humans, to only mammals, to all living beings. O'Sullivan agrees with Swimme and Berry (1992) who assume that all visible matter has the capacity for sentience. When spontaneity and sentience work together, the groundwork for the processes of integral development is established. O’Sullivan(1999) and Swimme and Berry(1992), consider that the ethical imperative of subjectivity is for humans to acknowledge their intimacy with other living things on the earth. This requires a transformation that begins from within. Abram (1996) calls for a "rejuvenation of our carnal, sensorial empathy with the 
living land that sustains us," by acknowledging the reciprocal nature of direct perception which presumes that "[e]ach of us [human and non-human] is both subject and object, sensible and sentient” (p. 67). About perceptual reciprocity, he states: “[It] may profoundly influence one's behaviour. If the surroundings are experienced as sensate, attentive and watchful, that I must take care that my actions are mindful and respectful, even when I am far from other humans, lest I offend the watchful land itself” (Abram, 1996, p. 69). James Conlon, an advocate for GeoJustice, believes that one's inner psyche is directly connected to the inner harmony of the planet; Conlon (1990) states: "As our awareness of the Earth deepens, we often undergo profound changes...The energy of our new awareness must be invested in transforming ourselves as well as structures and systems" (p. 76-77). Conlon believes that the ethical imperative of subjectivity is to connect one's fragmented inner life with the separateness of the cosmos in a way that promotes inner harmony and planetary peace. Deborah Orr, who has studied the work of philosophers Wittgenstein and Nagarjuna, believes that the mandate of subjectivity is soul development; Orr (as cited in Miller, 2005) defines the human soul as an embodied entity that is designed for intimacy in relationship with all that surrounds it, human and non-human (p. 234). O’Sullivan (1999) calls this intimacy the sacred depth of "the soul" ( p. 261) which carries the "numinous mystery" of the universe (p. 232).

In terms of transformative education, subjectivity is the most controversial principle of integral development because of the spiritual aspect of its implementation. O'Sullivan (1999) emphasizes, however, the essential need for education towards the nourishment of the "nonphysical, immaterial...energies, essences and part of us that existed before and will continue to exist after the disintegration of the body" (pp. 259-60). He states: "[E]ducators must take on the concern of the development of the spirit at a most fundamental level” (O'Sullivan, 1999, p. 259). When the principle of subjectivity is considered within the educational system, it becomes a process of dynamic, human, integral development that begins with the acceptance of each child as a unique individual with interior depth and potential for co-creation. Education then involves aesthetic, emotional, imaginative, moral, and intellectual formation, which targets the development of each child's interiority, creativity, and spirituality. Educators such as John P. Miller (2005), Thomas Moore (1994), Rachel Kessler (2000), and Leslie Owen Wilson (2004) advocate that in all situations and subject areas, educators must teach the "whole" child as a person with emotions, intuitions, interests, desires, feelings and moods that are integral to his or her being. Teaching must be more than transmitting knowledge; it must employ the art of moral perception (Garrison, 1997), which takes into account the interior aspects of the child's artistic, intellectual, interpersonal and physical expressions. The principle of subjectivity will work to balance the feelings of fragmentation, disconnection and alienation that our Western culture has created. When students and school communities are valued and validated, then the process of being and becoming can take hold.

This process directly connects to O’Sullivan's (1999) principle of communion. He states: "To be, is to be in relation. Much of our existence finds ultimate fulfillment in relatedness. The intricacy of our personal world is embedded in community" (p. 192). Within the framework of integral development, communion, along with differentiation and subjectivity, must exist as a dynamic evolutionary process that organizes and regulates itself. When individualism is overemphasized in the differentiation process, egocentrism results. When the interiority basis of subjectivity is undermined, autism occurs. Both lead to alienation, which is rampant in Western society, where humans find themselves trapped in a world of autonomous individuals that are incapable of connecting with the world outside of themselves. "Even when there is a sense of 
community, the community is limited to the human; the world outside the human is excluded" (O’Sullivan, 1999 p. 193). O’Sullivan's (1999) principle of communion is founded on the concept of the person as an integral component of a deep, relational totality; in other words, there is no sense of the individual as separate from community. O'Sullivan believes that as persons, we have a need for intimacy and for being present to one another at our deepest levels of subjectivity. This need extends to the wider context of both our natural world and the entire universe, and it involves the development a reciprocal relationship between subject and object, which he calls “cosmological sense” (p. 226). O'Sullivan traces the three-stage primal matrix of the human in community as developed by Stanislav Grof: (a) Perinatal gives a sense of belonging and trust; (b) I-Consciousness gives a sense of personal integrity, centeredness, and capability; and (c) Transpersonal which gives a sense that self is world and world is self. O'Sullivan (1992) explains that if any of these developments are interrupted, disconnection will result, and he believes that "a relationship of communion is an antidote” (p. 228) for those who have become alienated from the nurturance of the natural world. He believes that moving beyond the individualized self into an ecological self with cosmological sense involves communal identification with three entities: the personal (relationships with friends, family, pet, school, clubs, nation, continent), the ontological (a deep spiritual relationship with all existence), and the cosmological (a realization that our unfolding transformative story is the unfolding story of the universe through space and time). About communion and the ecological self, O’Sullivan , (1999) states:

Of one thing we can be sure; our own future is inseparable from the future of the larger life community which brought us into being and sustains us in every expression of our human quality of life; in our aesthetic and emotional sensitivities, in our intellectual perceptions, in our sense of the sacred as well as in our physical nourishment and our bodily healing. (p. 231)

In terms of developing communion, schools and classrooms need to provide supportive, nurturing and forgiving atmospheres whereby students can experiment with interconnective processes of bonding with others and the natural world. School communities must be safe places where all students know they belong and where students are encouraged to develop subjective communication with those who are different. Students need to be taught appreciation and tolerance for both individuals and social structures different from their own, and they need to know that they are capable, connected and contributing members who are responsible to the school community and the wider ecological community. Educating for communion within integral development will allow students to question, explore possibilities and test the limits as they begin to recognize the deep interiority and interconnectedness of all beings; this bonding will foster a paradigm shift in which students will come to realize that the needs of the individual, the needs of the school community and the needs of the earth are interdependent.

O’Sullivan's (1999) theory of integral development provides a logical framework for educational systems that are in need of re-creation. Transformative education emerges when differentiation, subjectivity and communion, the three principles of creativity, work together simultaneously. An integral developmental framework provides a supportive structure for implementing the educational renewal suggested by the Saskatchewan Ministry of Education Document, Renewed Objectives for the Common Essential Learning of Critical and Creative Thinking (CCT) and Personal and Social Development (PSD). 


\section{Educational Renewal: Towards Critical and Creative Thinking, Personal and Social Development, and a Global and Planetary Ethic}

The Saskatchewan Ministry of Education's Common Essential Learning document entitled Renewed Objectives for the Common Essential Learning of Critical and Creative Thinking (CCT) and Personal and Social Development (PSD) is a 266 page educational project that focuses on holistic and value-based emotional, social and spiritual development. When one looks at the elements of CCT, PSD and integrated CCT/PSD, it is evident that practices that foster their implementation will require a framework that supports movement and flexibility within educational systems. An integral development framework will serve as a suitable vehicle for creative and effective implementation of this document for several reasons:

- The principles of differentiation, subjectivity and communion provide an excellent theoretical basis for anti-oppressive, anti-racist, anti-sexist education in our province.

- The principles of integral development place value on Indigenous ways of knowing and being, and recognize the importance of balanced spiritual, mental, emotional and physical development and lifelong learning.

- The principles of integral development celebrate the uniqueness, inner life, and interconnectedness of all cultures that are brought together within the school system. They encourage a "sharing of stories" among those who are uniquely different from each other.

- The principles of integral development provide a strong philosophical foundation for the creation of safe, respectful classroom and school communities where all people, regardless of intellectual or physical abilities, are respected and valued as capable, contributing, and connected members.

- The principles of integral development balance dualized thinking in terms of standardization and competitive educational practices. They present a strong philosophical argument for arts-based education, which celebrates the uniqueness of each individual and gives voice to the "inner being" of each student's identity. Educators must have a philosophical framework by which to demonstrate the value of fostering creativity and imagination in their teaching practices.

- The principles of integral development balance dualized thinking in terms of multiple intelligences and abilities. They present a strong philosophical argument for the "unique giftedness" of individuals in the areas of naturalistic intelligence, interpersonal intelligence, intrapersonal intelligence, artistic intelligence, musical intelligence and kinesthetic intelligence (Gardner, 1993). In an era where all students are evaluated by the "same" means of verbal/linguistic and mathematical intelligences, the principles of integral development present a valid argument for assessment and evaluative practices which value other ways of knowing and learning.

- The principles of integral development serve to re-connect students to themselves, their communities, and the natural world. In an era of technology and convenience, where young people are becoming increasingly more isolated from interpersonal communication practices and personal experiences with nature, educators can find in integral development a justification for providing educational opportunities that are 
designed to build mutually enhancing human-human interconnections and human-natural world interconnections.

- The principles of differentiation, subjectivity and communion provide an excellent theoretical basis for the purposes of discussion about the assessment of specific teaching and learning practices that require renewal and recreation within individual schools.

- Integral development provides a philosophical framework that allows for gradual transformation of existing educational practices. In addition, teachers who are interested in developing a transformative vision of education will need a structure by which they are supported and valued as they attempt to implement suggestions for renewal (especially in the area of spiritual development) that may meet with resistance from parents and the greater community.

- Because differentiation, subjectivity, and community are evolving practices that are unique to the needs of each situation, integral development provides a framework that will enhance dynamic re-ordering and re-creating of educational objectives and practices in such a way that the integrity of existing educational structures will not be threatened.

- Integral development employs the principles of differentiation, subjectivity and communion to link transformative education to the wider processes of creativity within the universe in order to create a foundation for a necessary paradigm shift to occur in Western education.

Specifically, integral development addresses the following stated aims and goals of the Saskatchewan Education document:

1. CCT Aim: To graduate persons who use the full range of thinking abilities needed for personal growth and full participation in diverse and changing contexts.

CCT Goals: To create a climate of openness, mutual respect and support. To develop knowledge, values, skills/abilities for critical and creative thinking, and to integrate these creative dispositions to meet learning needs and real life challenges.

2. PSD Aim: To support children and youth in becoming authentic, confident and caring persons who use their understanding of self, others and the natural world in positive, sustaining ways.

PSD Goals: Students will experience being valued and respected. They will understand, value and care for self, others and the natural world, and they will contribute to co-operative endeavors, the growth of mutual understanding and the creation of a better world for all.

3. CCT and PSD Integrated Aim: To support the development of persons who recognize the intrinsic value of caring, inclusive, democratic and sustainable communities and have the abilities needed to act on this recognition.

CCT and PSD Integrated Goals: To experience membership in caring, respectful and democratic classroom and school communities. To use personal integrity, "fair minded" critical thinking and strong creative abilities to make decisions and to generate and evaluate alternatives related to moral values, issues and concerns. (Finney, 2008, pp. 4-10)

Each of these principles is further developed as follows: 
ELEMENTS OF CRITICAL AND CREATIVE THINKING

Integrated Abilities
Thinking Contextually
Central Learning Processes
PERSONAL
GROWTH
Aritical Thinking
Abilities
Understanding and Valuing FuLL
PARTICIPATION
IN DIVERSE

Figure 1. Elements of critical and creative thinking.

ELEMENTS OF PERSONAL AND SOCIAL DEVELOPMENT

\begin{tabular}{lll} 
Diversity & & \multicolumn{1}{c}{ Character/Moral } \\
Interdependence & & Development \\
Sustainability & & \\
& AUTHENTIC & \\
Spiritual & CONFIDENT & Identity and \\
Development & CARING & Self-knowledge \\
& CONTRIBUTING & \\
Social Interaction & & \\
Skills, abilities & & Social Commitment \\
& & Service \\
& & Social Action
\end{tabular}

Note: Growth in one area promotes growth in another

Figure 2. Elements of personal and social development. 
ELEMENTS OF CCT AND PSD INTEGRATED

\begin{tabular}{|c|c|c|}
\hline Moral Opportunities & & Moral Reasoning \\
\hline And Challenges & & Process \\
\hline \multicolumn{3}{|l|}{ Within Daily Life } \\
\hline & CARING & \\
\hline & INCLUSIVE & \\
\hline & DEMOCRATIC & \\
\hline & SUSTAINABLE & \\
\hline & COMMUNITIES & \\
\hline \multicolumn{2}{|l|}{ Global and } & Communication \\
\hline \multicolumn{2}{|l|}{ Planetary Ethic } & Thinking and Dial \\
\hline
\end{tabular}

Figure 3. Elements of CCT and PSD integrated.

These elements suggest a structural framework for development which could lead to generating renewal that re-frames a movement and creates a shift from product-oriented, individualized educational pursuits to organic, connected, and value-based educational processes. Teaching objectives in all three specific areas are consistent with the integral developmental principles of differentiation, subjectivity, and communion. In the area of differentiation, teachers are encouraged to treat each student as a whole person of innate worth, to affirm unique abilities and potential, and to appreciate "unique perspectives" (Finney, 2008, p. 39). In addition, teachers are asked to embrace diversity within the context of real life situations by emphasizing that there are many different ways of doing things, and that difference is necessary and often enriching. The following quotation appears as a reflection in the conclusion of the CCT section:

Because you are the unique product of evolution, culture, environment, fate, and your own quirky history, what is obvious and humdrum to you is guaranteed to be thoroughly original....Paradoxically, the more you are yourself, the more universal your message. (Nachmanovitch, 1990, as cited in Finney, 2008, p. 84)

In the PSD section, human diversity is addressed in terms of gender, sexual orientation, abilities/disabilities, culture/ethnicity/race/language, and income (Finney, 2008, p. 134), and biodiversity is explored as an interdependent process necessary for enrichment, continuance and renewal of life. The PSD section of the renewal document also places emphasis on the integral development principle of subjectivity. Teachers are encouraged to integrate the arts and the natural environment in open-ended lessons that support moral, emotional, and spiritual growth and foster a sense of awe and mystery. In addition, they are encouraged to treated creativity as an internal process motivated by curiosity, determination, and passion rather than by external rewards such as praise, recognition, and good (Finney, 2008. p.97). The elements of PSD address the following five developmental areas that pertain to three evolving principles of integral development: 
- spiritual development - the concept of inner self; exploration of thoughts, feelings and beliefs; questions of meaning and purpose; appreciation and gratitude for all life has to offer;

- identity development-self-understanding and self-care; support for intellectual, emotional, relational and spiritual needs; emotional intelligence;

- character/moral development-responsibility for one's thoughts, words, actions; understanding of the difference between a person and his or her behaviour;

- diversity, interdependence, and sustainability-valuing and respecting human and biological diversity; developing understanding of our social and environmental interdependence and the values and abilities related to sustaining life; and

- social interaction, skills and abilities-basic interpersonal skills; respectful communication; cooperation; conflict prevention and resolution, and social commitment, service and social action.

The elements of integrated CCT/PSD focus on all of the above areas; in addition, they target the development of "values and abilities needed for the growth of communities that are caring, inclusive, democratic and sustainable” (Finney, 2008, p. 255). They also foster communitarian thinking and dialogue, which is founded upon a basic belief in, and commitment to the values of mutuality, empowerment, reciprocity and sustainability within the global community. This commitment is consistent with O'Sullivan's (1999) communion principle, which centers on the development of the ecological self and the attainment of cosmological sense.

The visionary document Renewed Objectives for the Common Essential Learning of Critical and Creative Thinking (CCT) and Personal and Social Development (PSD) warrants a philosophical framework that supports its implementation. Educators must take seriously its comprehensive exploration of renewal processes for Western educational institutions, but the task seems monumental without a framework that allows for assessment of present day practices and for dynamic evolutionary movement within the existing educational system. It makes sense that principles of O'Sullivan's (1999) integral development framework be used to begin the "hopeful" process of value-based social and spiritual renewal within the realm of education at this critical moment in time. O’Sullivan (1999), in an essay entitled “Emancipatory Hope” refers to the message of Paulo Friere, whose words are appropriate to the implementation of Finney's (2008) committee's renewal vision within the democratic and multicultural nature of Saskatchewan society: "Without a minimum of hope, we cannot so much as start the struggle...Hence the need for a kind of education in hope” (Friere, 1996, p. 9). O'Sullivan's (1999) own vision is not unlike that of the Saskatchewan renewal committee; it makes sense that his philosophical theories be used as a framework for developing a total school atmosphere in which people live their values and work together for the common good. In this, the United Nations Decade of Education for Sustainable Development (2005-2014), when educators are being asked to integrate the principles, values and practices of sustainable development into all aspects of education, Saskatchewan's Ministry of Education has taken a leading role with the creation of this document, and has the potential to continue breaking ground in transformative education with its implementation. 


\section{Integrated Value-Based Education For the Future: A Personal Perspective}

From personal experience as a former high school teacher in Saskatchewan, I believe in the values that the Saskatchewan Ministry of Education document promotes, and I am convinced that education of the future must provide more opportunities for value-based, integrated learning and teaching. In my last teaching assignment in an inner city high school with a large Aboriginal and multicultural population, the environment in my classroom was such that each person was recognized as a capable, contributing, and connected member of a respectful community. In that class, which was composed of students from all academic levels, we redefined the word success to mean that each individual has a unique set of gifts and talents that he or she can discover and utilize to make the world a better place. Students tapped into their own creativity; they connected with nature; they embraced silence and stillness; they experimented with "other" ways of knowing and learning, and they reawakened their sense of mystery and awe. Most of all, they recognized (many for the first time) that they had something valuable to offer to each other, the community and the greater world. Many of my students were people who had not been motivated to "achieve" in school previously because they did not perform well on paper and pencil tests, and this lack of success contributed to the high dropout rate in the school. In 3 years and 6 semesters of using a foundation that drew on value-based philosophy, not one of my students failed or dropped out of my class. Two research projects connected to the class indicated that the elements of social and personal development, critical and creative thinking, and spiritual and moral discernment were the strengths in the process. At that time, I did not know about integral development, but I have since found that the principles of differentiation, subjectivity, and communion provide a strong philosophical support for the kind of integrated learning that my class provided and that the Saskatchewan Ministry of Education document promotes.

I believe that all teachers should become aware of the CCT/PSD document, and they should learn how to use it. That is why the document is required reading in my Educational Foundations class, which is entitled, Perspectives in Educational Values. I have challenged my students to use this document as a resource to create the foundations for safe, inclusive, and welcoming classrooms, to envision a mutually enhancing human-nature interconnectedness, to investigate teaching and assessment practices that foster and utilize multiple ways of learning and knowing, and to integrate value-based perspectives into their philosophies of education. It is my hope that these teachers of the future will develop a "generative vision that will challenge their own creativity in the specific educational context of their own work" (O’Sullivan, 1999, p. 9) in order that they might "awake to the splendor of the universe [and] ignite life in others" (Swimme, 2001, p. 61). 


\section{References}

Abram, D. (1996). The spell of the sensuous. New York, NY: Vintage Books.

Berry, T. (1988). The dream of the earth. Los Angeles, CA: Sierra Club Books.

Conlon, J. (1990). Geo-Justice. Winnipeg, MB: Hignell Printing Ltd.

Dewey, J. (1916). Democracy and education. Norwood, MA: McMillan Company.

Finney, S. (2008). Renewed objectives for the common essential learning of critical and creative thinking (CCT) and personal and social development (PSD). Regina, SK: Saskatchewan Ministry of Education.

Freire, P. (1996). Pedagogy of hope. New York, NY: Continuum.

Gardner, H. (1993). Frames of mind. New York, NY: Basic Books.

Garrison, J. (1997). Dewey and Eros. New York, NY: Teacher’s College Press.

Kessler, R. (2005). Nourishing Adolescent Spirituality. In J. Miller, S. Karsten, D. Denton, D. Orr, \& I. Colalillo Kates (Eds.), Holistic learning. Albany, NY: State University of New York Press.

Miller, J., Karsten, S., Denton, D., Orr, D., \& Colalillo Kates, I. (Eds.) (2005). Holistic learning. Albany, NY: State University of New York Press.

Moore, T. (2005). Educating for the Soul. In J. Miller, S. Karsten, D. Denton, D. Orr, \& I. Colalillo Kates (Eds.), Holistic learning. Albany, NY: State University of New York Press.

Orr, D. (2205). Minding the Soul in Education. In J. Miller, S. Karsten, D. Denton, D. Orr, \& I. Colalillo Kates (Eds.), Holistic learning. Albany, NY: State University of New York Press.

O’Sullivan, E. (1999). Transformative learning. Toronto, ON: University of Toronto Press.

O’Sullivan, E. (2005). Emancipatory hope. In J. Miller, S. Karsten, D. Denton, D. Orr, \& I. Colalillo Kates (Eds.), Holistic learning. Albany, NY: State University of New York Press.

Purpel, D. \& McLaurin, W. (2004). Reflections on the moral and spiritual crisis in Education. New York, NY: Peter Lang Publishing.

Swimme, B. (2001) The universe is a green dragon. Rochester: Bear \& Company.

Swimme, B., \& Berry, T. (1992). The universe story: An autobiography from planet Earth. San Francisco, CA: Harper and Row.

Wilson, L. (2005). Listening to ancient voices. In J. Miller, S. Karsten, D. Denton, D. Orr, \& I. Colalillo Kates (Eds.), Holistic learning. Albany, NY: State University of New York Press. 